\title{
Management of the aggressive emergency department patient: non-pharmacological perspectives and evidence base
}

This article was published in the following Dove Press journal: Open Access Emergency Medicine

\author{
Sandra K Richardson (1D ${ }^{1,2}$ \\ Michael W Ardagh ${ }^{1,3}$ \\ Russell Morrison (iD ${ }^{4}$ \\ Paula C Grainger (D) \\ 'Emergency Department, Christchurch \\ Hospital, Canterbury District Health \\ Board, Christchurch, New Zealand; \\ ${ }^{2}$ Centre for Postgraduate Nursing \\ Studies, University of Canterbury, \\ Christchurch, New Zealand; \\ ${ }^{3}$ Department of Surgery, University of \\ Otago, Christchurch, New Zealand; \\ ${ }^{4}$ Well-being Health and Safety Team, \\ Canterbury District Health Board, \\ Christchurch, New Zealand
}

Introduction: Aggression in the Emergency Department (ED) remains an ongoing issue, described as reaching epidemic proportions, with an impact on staff recruitment, retention, and ability to provide quality care. Most literature has focused on the definition (or lack of) core concepts, efforts to quantify the phenomenon or provide an epidemiological profile. Relatively little offers evidence-based interventions or evaluations of the same.

Aim: To identify the range of suggested practices and the evidence base for currently recommended actions relating to the management of the aggressive Emergency Department patient.

Methods: A meta-synthesis of existing reviews of violence and aggression in the acute health-care setting, including management of the aggressive patient, was undertaken. This provided the context for critical consideration of the management of this patient group in the ED and implications for clinical practice.

Results: An initial outline of issues was followed by a systematic search and 15 reviews were further assessed. Commonly identified interventions are grouped around educational, interpersonal, environmental, and physical responses. These actions can be focused in terms of overall responses to the wider issues of violence and aggression, targeted at the pre-event, event, or post-event phase in terms of strategies; however, there is a very limited evidence base to show the effectiveness of strategies suggested.

Clinical Implications: The lack of evidence-based intervention strategies leaves clinicians in a difficult situation, often enacting practices based on anecdote rather than evidence. Local solutions to local problems are occurring in a pragmatic manner, but there needs to be clarification and integration of workable processes for evaluating and disseminating best practice.

Conclusion: There is limited evidence reporting on interventional studies, in addition to identification of the need for high quality longitudinal and evaluation studies to determine the efficacy of those responses that have been identified.

Keywords: aggressive patient, management of violence, emergency department, violence and aggression

\section{Introduction}

Violence continues to be problematic in the emergency health-care setting. It has been variously described as alarming, ${ }^{1}$ escalating, ${ }^{2}$ at crisis level, ${ }^{3}$ and even at epidemic proportions. $^{4,5}$ Evidence continues to emerge demonstrating that health-care violence and aggression occur in a range of countries, across varied geographical settings, socioeconomic levels and within services offering varying technological capacity. ${ }^{6-8}$ While the presence of violent outbursts and associated aggression may not be a new
Correspondence: Sandra K Richardson Emergency Department, Christchurch Hospital, 2 Riccarton Avenue, Christchurch 8140, New Zealand $\mathrm{Tel}+64273101675$

Email Sandra.richardson@cdhb.health.nz 
phenomenon, the ability to identify and share information rapidly has increased recognition of the extremes that present, and highlighted the issue in ways not possible before. This international awareness has benefits - not only is it raising the awareness of the extent and seriousness of the issue, but it also provides the opportunity to share learning and responses and to identify potentially transferrable or adaptable options from other services or countries.

\section{Background}

There is no simple, "one size fits all" remedy to the management of violence and aggression in the emergency department (ED). Reports identifying and describing violence and aggression in EDs have been produced for as long as EDs have existed. Emergency Medicine as a specialty typically dates from the 1960s in the $\mathrm{UK}^{9}$ and USA, ${ }^{10}$ and from the $1980 \mathrm{~s}-1990 \mathrm{~s}$ in parts of Asia and Europe. ${ }^{11,12}$ In other regions it is even more recently recognized as a specialty (India, parts of the Middle East and Africa) ${ }^{13-15}$ and so remains a relatively new field. Therefore, it is appropriate to look at the wider health-care arena for effective approaches to management of the aggressive patient. It is important to acknowledge that the ED environment has specific challenges, and has been identified as one of the areas of highest risk within the health sector. ${ }^{16-18}$ Within the ED setting, the workforce is not equally targeted - various studies have highlighted the rates and types of violence amongst different groups working in the ED. What is apparent is that nurses and health-care assistants, whether because of their higher levels of patient contact and potentially their perceived position in the hierarchy of the health system, are at risk of greater exposure to violence and aggression. ${ }^{18-21}$ Predictors of violence and aggression have been suggested, including patient behavior, background and condition (including organic derangements and presence of alcohol or drugs) $)^{22,23}$ as well as environmental and social stressors including prolonged waiting times, overcrowding, stress, anxiety, and pain. ${ }^{24-26}$ Additional consideration has been given to the individual skills of the practitioner with regard to communication, interpersonal interactions, clinical expertise, and individual personality traits and attitudes (such as self-confidence, resilience, and reflection). ${ }^{27,28}$ As well as being potential contributory factors, there is uncertainty whether certain character traits or clinician behaviors exist prior to exposure to violence or develop as a secondary, traumatic response. $^{29-32}$ Thus, any efforts to manage the aggressive patient must be mindful of the available breadth of resources (from outside the ED setting as well as within) and awareness of the potentially targeted nature and necessary focus for at-risk groups amongst staff. This enables the opportunity to draw on and adapt from generic approaches while building tailored programs and evidence-based responses.

Violence in the ED as a specialty area has been explored, with researchers looking to identify causality, prevalence, impact, and consequences. The overall body of literature has demonstrated problems with recognition, identification, and reporting of aggression - failure to consistently identify and record the issue limits the ability to compare findings and generate meta-analyses of studies. $^{29,32,33}$ Recognition of core risk and trigger factors has occurred across different settings, resulting in a number of educational and interventional tools being suggested. Measurement tools, risk assessment scales, and pre-emptive identification and scoring systems have been developed to enable rapid recognition and defusing prior to the escalation of situations. ${ }^{19,34-37}$ Focus has been placed on the need to design facilities and develop environmental strategies, to engage with communities and to draw on knowledge from communication, psycho-social, management, and other human interface knowledge bases. ${ }^{38,39}$ Changing social philosophies have seen movements in regard to physical interventions, with different countries responding to changed approaches and expectations and the associated movements to reduce the use of physical restraint, to increase physical security presence, or to increase/decrease the use of chemical sedation depending on the relevant social and clinical drivers. ${ }^{40-43}$ Heightened expectations from patients, and society in general, regarding health-care timeliness, possible treatment options, as well as entitlement and desirability of care options, are all seen as possible drivers for seeking ED care and, in turn, for at times responding in inappropriate ways within the ED setting. The issues related to the recognition of aggression and what this is, the concern for behavioral issues, psychiatric patients and changed provision of care needs to be considered. When is an aggressive patient considered a clinical concern, when a behavioral problem or when a social issue? The roles of police and social workers and responses to community expectations are relevant and influence the range of potential responses available to the clinician. The ED setting including varied access to additional services, interventions, behavioral emergency teams and ability to refer to other services, further limits or restricts the opportunities 
available. Despite these considerations, it is possible to identify a broad range of categories that relate to the responses available. Prior to focusing on the specific issues relating to the management of the aggressive patient, the generic issues contextualizing responses to violence in the ED setting are presented utilizing a Haddon matrix (Table 1). The Haddon matrix has been widely used in conceptualizing injury prevention threats and modeling solutions. It is presented as a formatted $3 \times 4$ grid with three rows representing the different temporal phases of an injury/incident - pre-event, event and post-event. The four columns identify the different influencing factors: host/vector, agent, physical environment, and social environment. $^{44}$

\section{Aim}

The intention of this study was to clarify the existing degree of evidence underpinning current management strategies used in dealing with aggressive and violent ED patients.

\section{Methods}

The approach was to review existing research for evidence-based recommendations relating to the management of the aggressive patient, and to identify what degree of support there is for commonly identified practices. In order to facilitate this, a meta-synthesis of existing literature reviews, with a preference for systematic reviews, was undertaken. It was recognized that a meta-analysis would not be possible given the highly disparate nature of the research available, and that a meta-synthesis would still enable a useful comparison and drawing together of core elements that might emerge.

\section{Search strategy}

For the purposes of this review, the management of the aggressive patient was limited to interventions presented at the broader level, rather than investigations of individual cases, underlying organic causes of agitation, or efficacy of specific drugs used as part of a pharmacological sedation or management intervention. The focus was on identifying suggested best practice responses to the expression of violence or aggression by patients, and the degree of underpinning evidence. The research question for this topic was set as "to identify the range of suggested practices and determine the evidence base for currently recommended actions in relation to management of the aggressive Emergency Department patient”. An initial scoping exercise looked for systematic, integrative or narrative reviews which incorporated management of the aggressive patient in the ED environment. This was subsequently expanded to include responses to violence and aggression in the broader health sector, with sections relating to the management of aggression toward health-care workers. The search was undertaken in MEDLINE (Ovid), CINAHL, PsychInfo, Cochrane database of Systematic Reviews, Joanna Briggs Library and a text search of Google Scholar using combinations of literature review, systematic review, narrative review, review; violence and aggression, behavioral emergency; health-care worker, emergency department, hospital. Inclusion criteria were that the work was related to the acute health-care workforce setting, had as its major focus violence and aggression toward staff and included a significant section which addressed management of the violent patient. English language only reviews were sourced; no lower date limitations were set; and review publications through to May 2019 were considered. Reviews which focused solely on use or comparison of specific pharmaceuticals, focused solely on staff emotional states, provided only brief mention of risk factors or recognition of violence triggers as part of an overview and omitted aggression management activities, or which focused on determining prevalence levels were excluded. Figure 1 outlines the search strategy, based on the process recommended by PRISMA, ${ }^{45}$ and Table 2 details the reviews included for analysis. The intention was to develop an overview or umbrella review of existing reviews and to use this to provide the context within which to identify the current evidence for the management of the aggressive patient, in the setting of the emergency department.

\section{Analysis}

The reviews incorporated in this meta-synthesis were aggregated in line with the principles of Braun and Clarke's thematic analysis ${ }^{59}$ and synthesis to generate a narrative representation of the key themes that emerged. Despite the implied methodological similarities (for example, the reference to systematic review methodology, $n=7$ ), even within similar approaches, there was considerable variability in the way in which the reviews were undertaken. This heterogeneity limited the opportunity for direct comparison and lack of consistent application of review processes is increasingly recognized. Despite this, many of the reviews were robust, and a number specifically identified issues with the quality of the research and evidence 


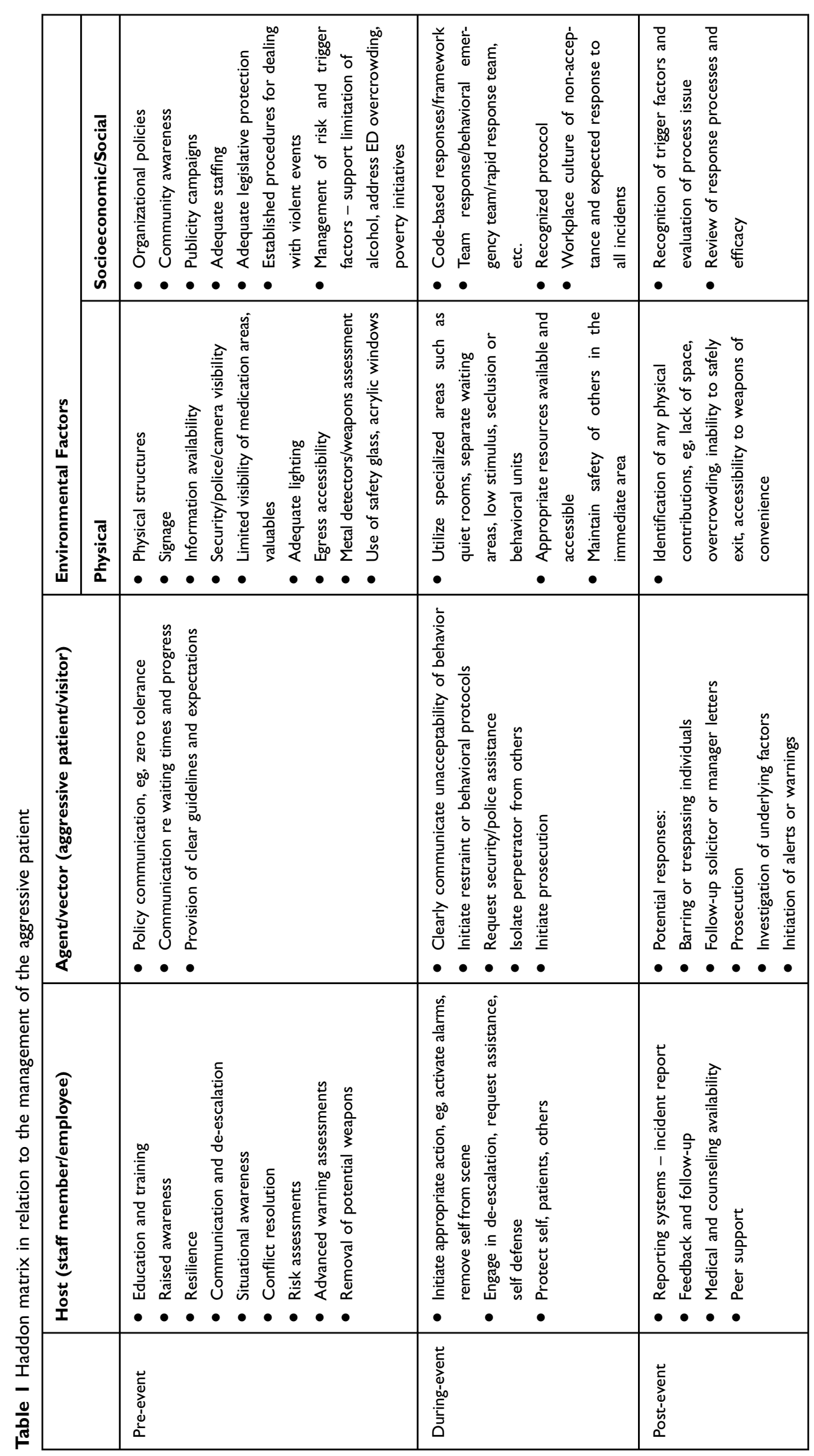




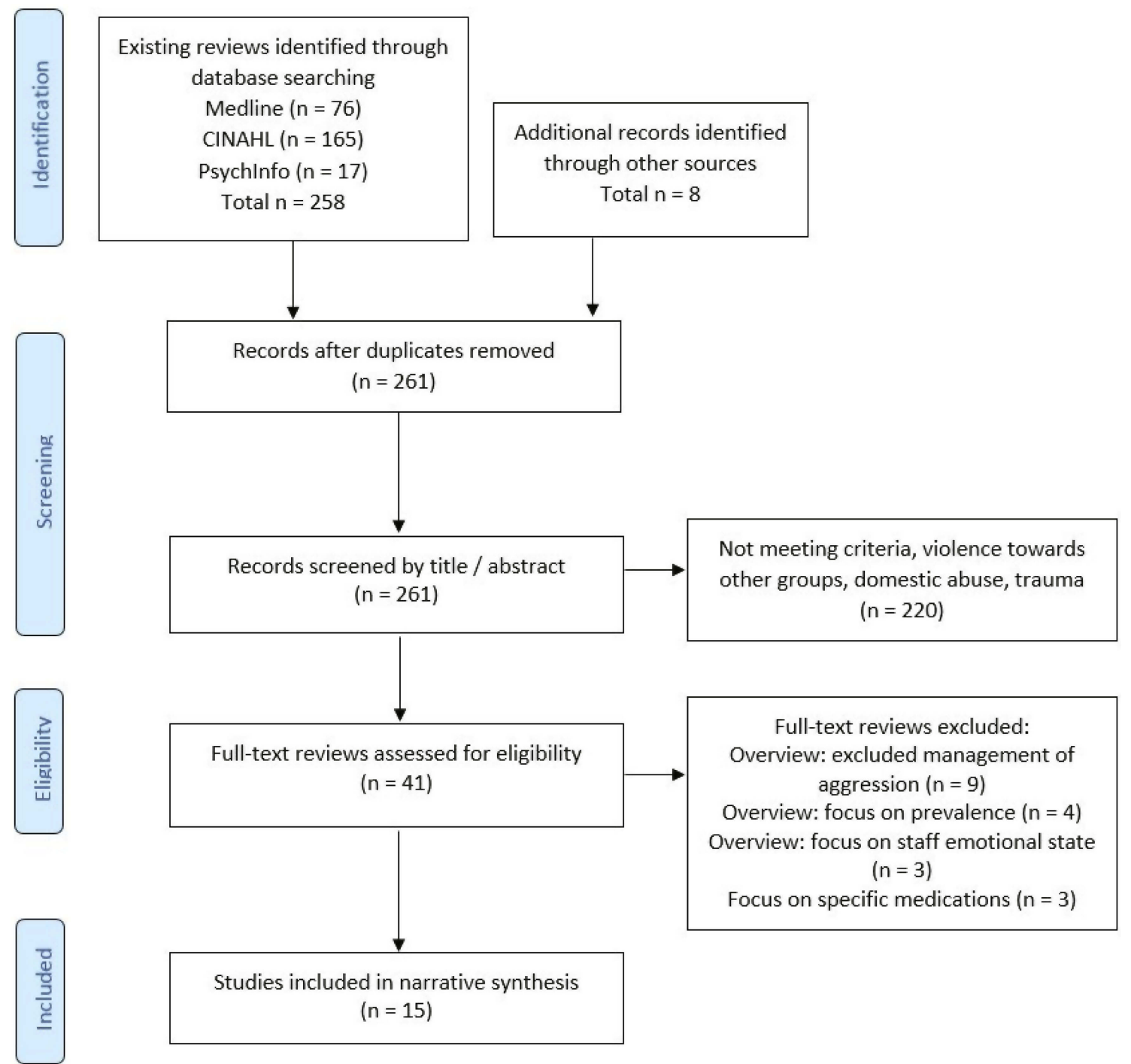

Figure I Search strategy and retrieval of studies for review.

base of articles available for review. ${ }^{32,48,50,53,54}$ All the reviews identified the need for further research into various aspects of the topic, with many specifying the need for more intervention studies, evaluation, and recognition of specific interventions for which there was either limited or no evidence available.

\section{Findings}

\section{Data summary}

An initial finding of 261 reviews was identified, reduced to 41 following a preliminary screening of title/abstract and removal of those that were clearly outside the topic of interest. The full text of these reviews was then read and assessed against the inclusion/exclusion criteria for this meta-synthesis, with 15 retained. The included reviews were published between 2001 and 2018. The authors were associated with the following countries: Australia $(\mathrm{n}=7) ;^{32,46-51}$ Europe $(\mathrm{n}=2) ;{ }^{35,52}$ UK $(\mathrm{n}=3) ;{ }^{53-57}$ USA $(\mathrm{n}=3) .{ }^{56-58}$ The review articles were self-identified as being systematic reviews $(n=7)$, and one each of descriptive review, training program review, brief review, narrative review, literature review, scoping review and one did not identify a specific type. The core elements of the review data extraction relevant to the management of the aggressive patient are presented in Table 2.

\section{Education and communication strategies}

The 2018 systematic review by Edward et $a^{53}$ sought to identify existing non-pharmacological brief interventions (BIs) used to de-escalate acute behavioral disturbances, 


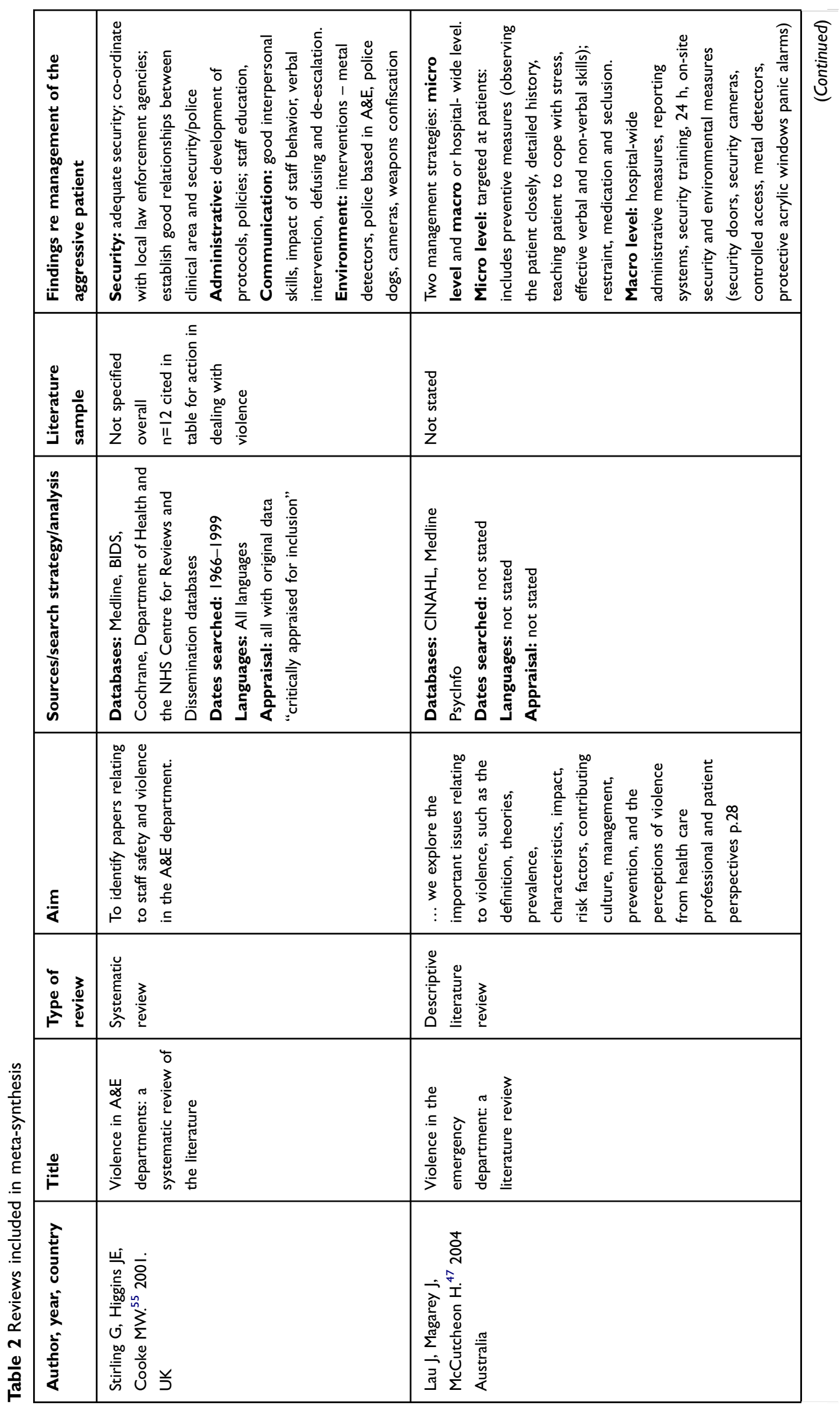




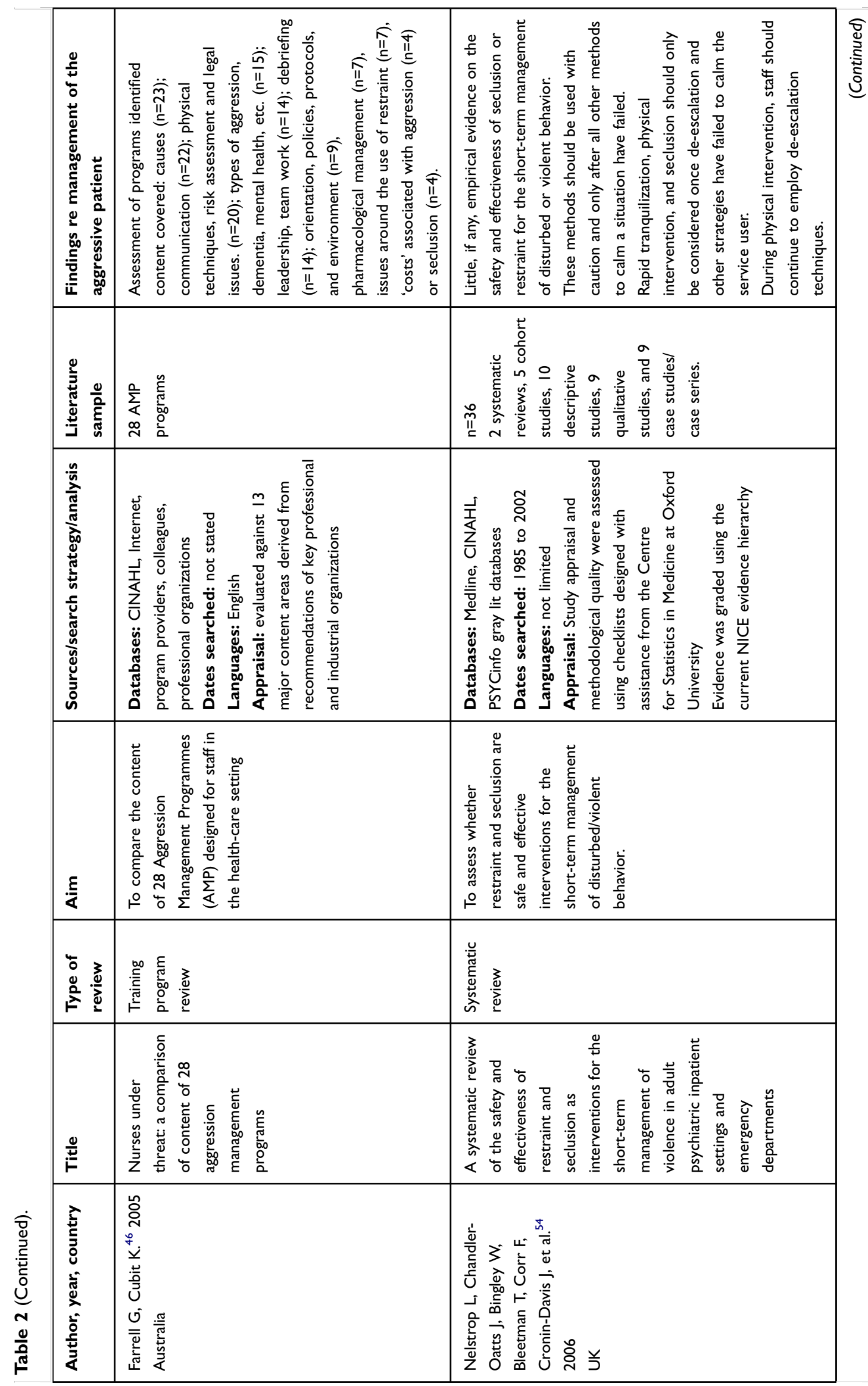




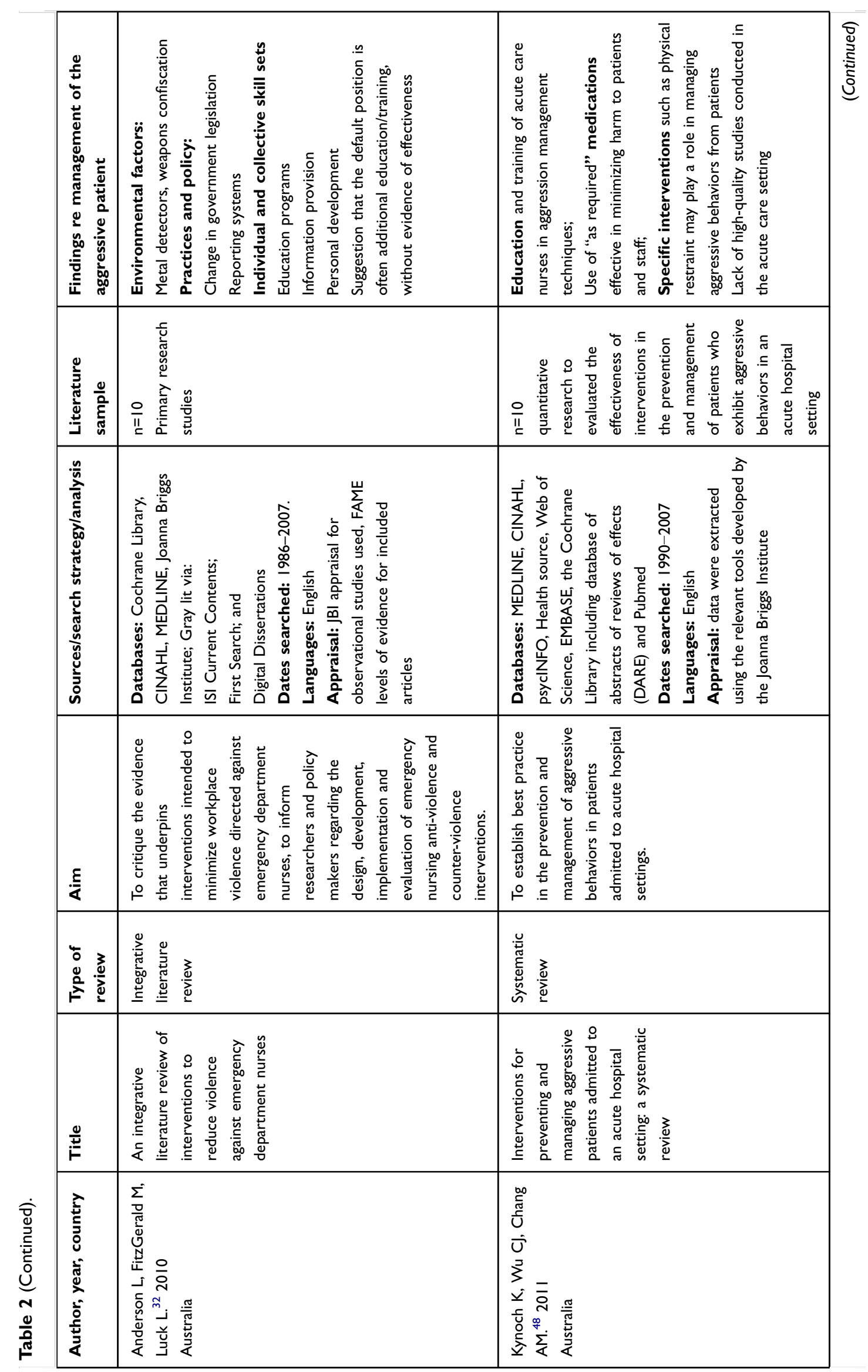




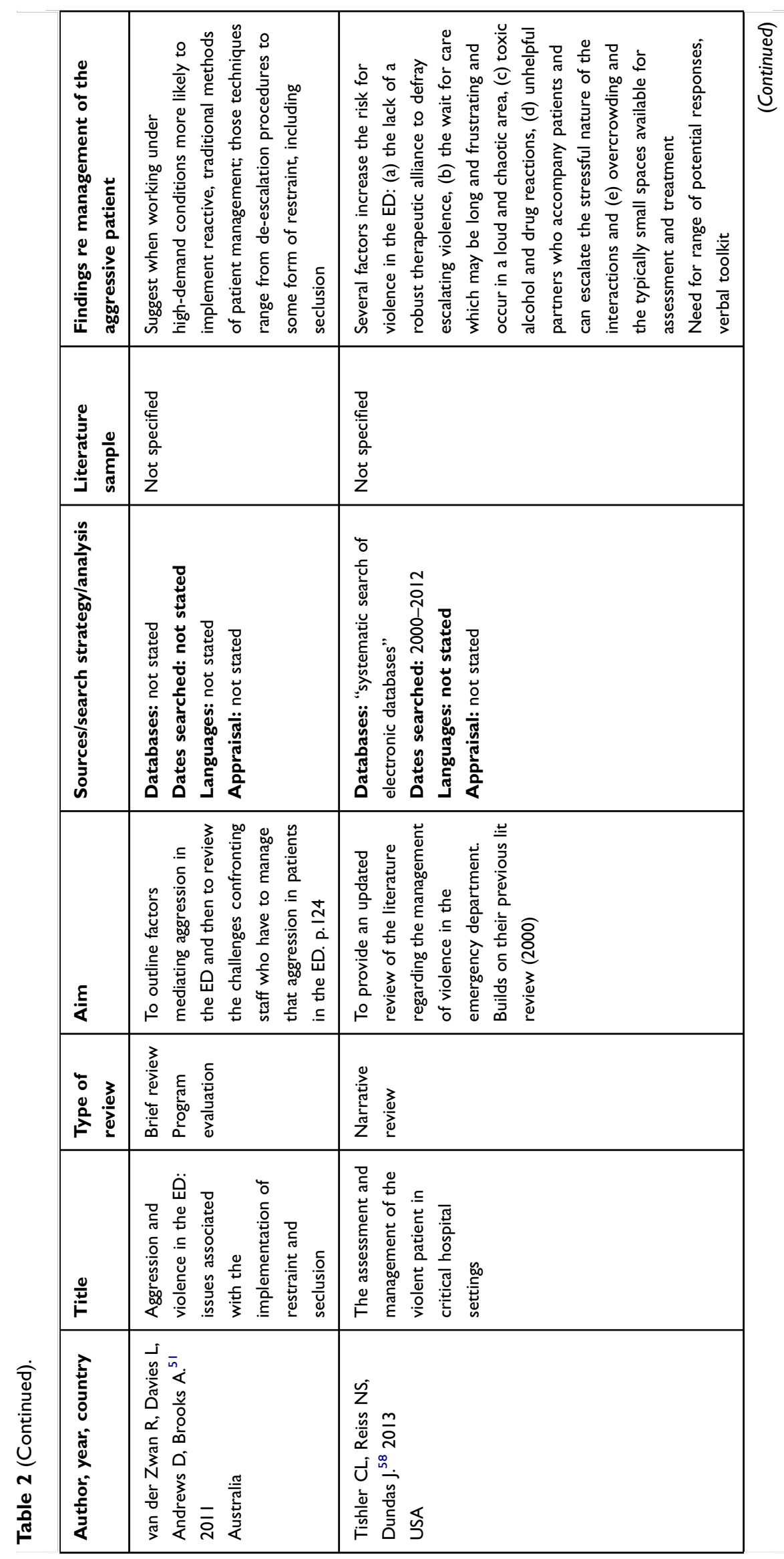




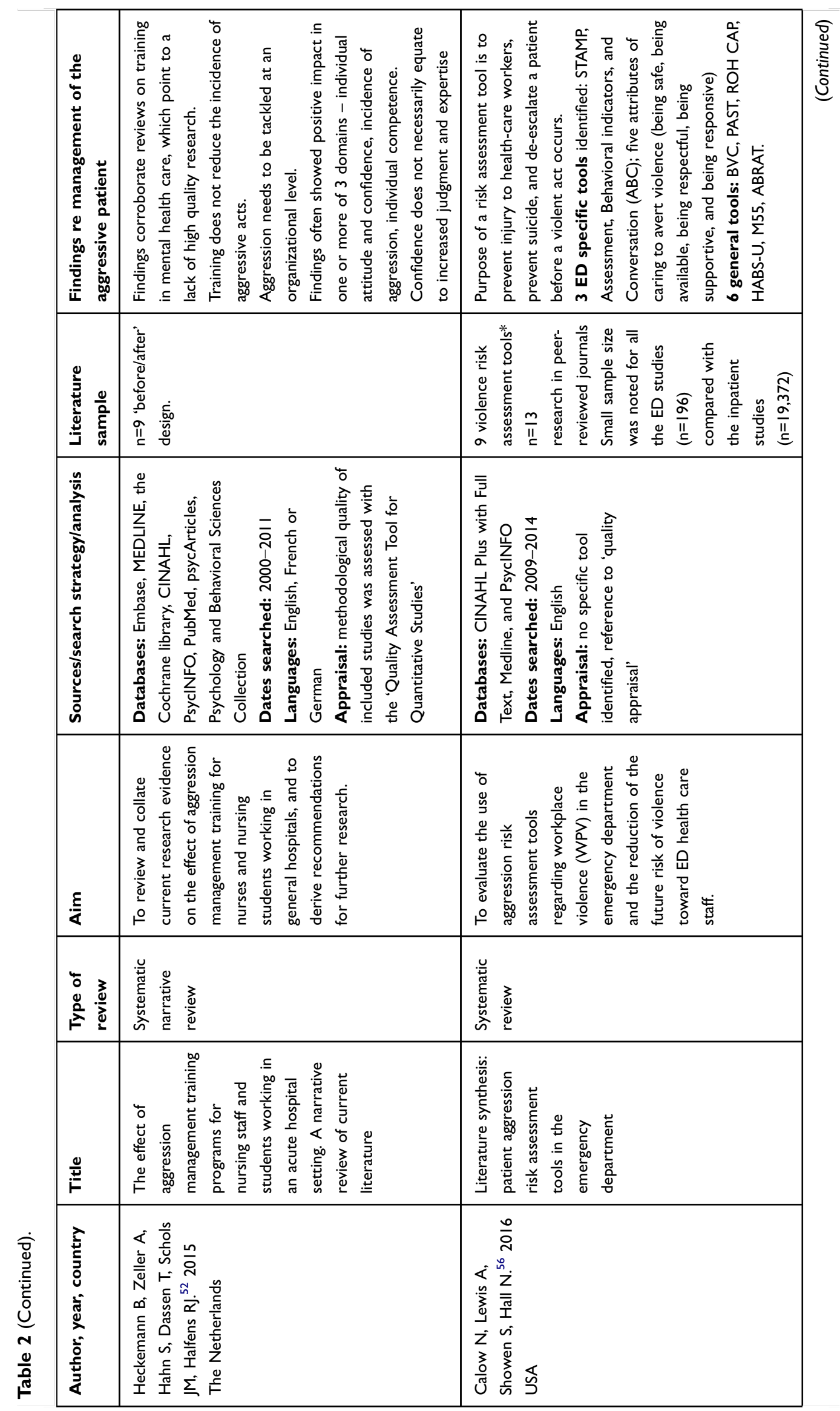




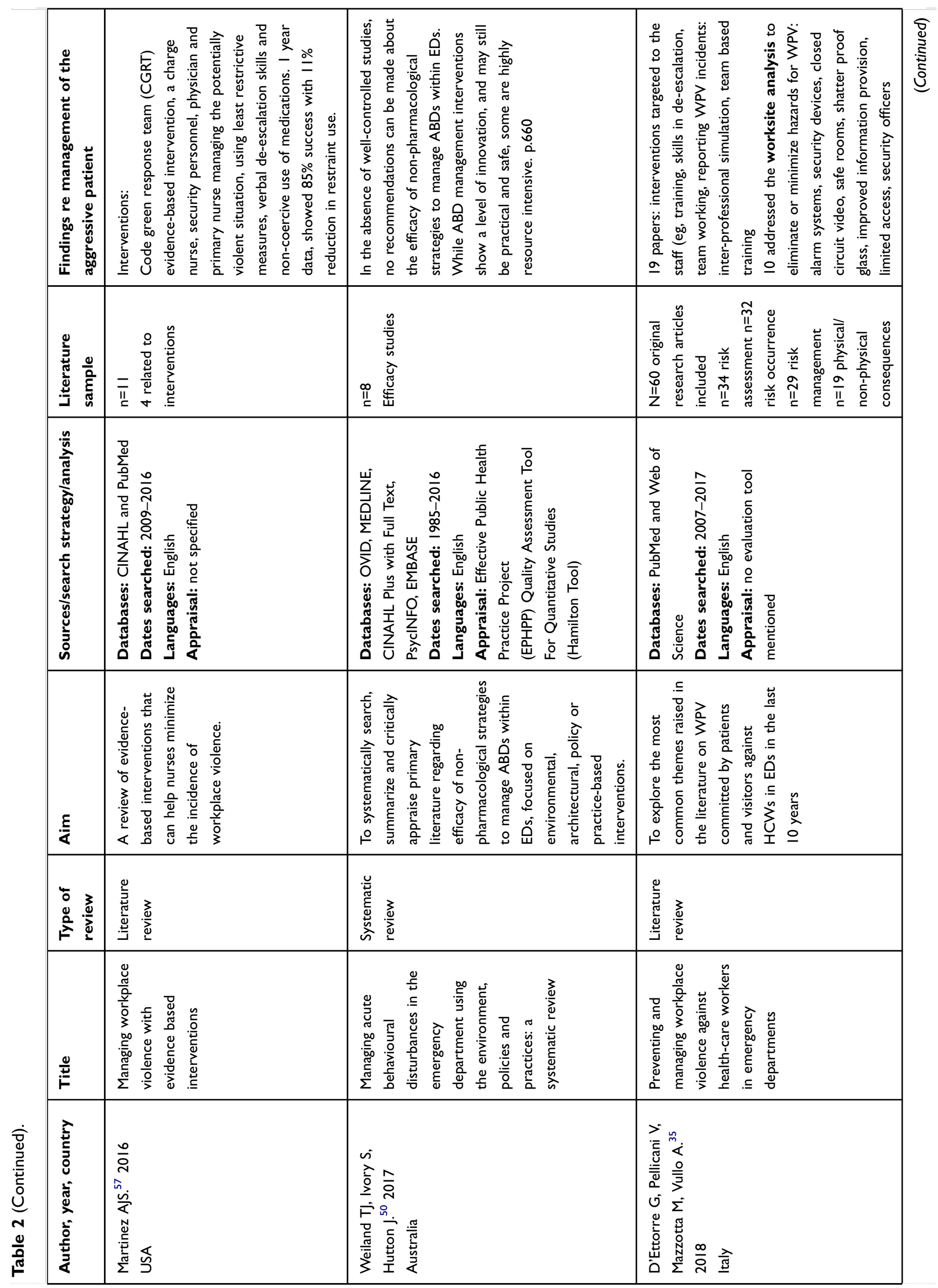




\begin{tabular}{|c|c|c|}
\hline 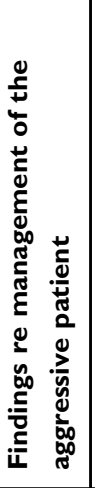 & 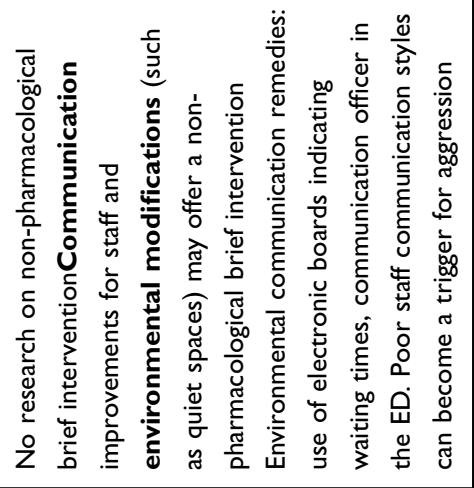 & 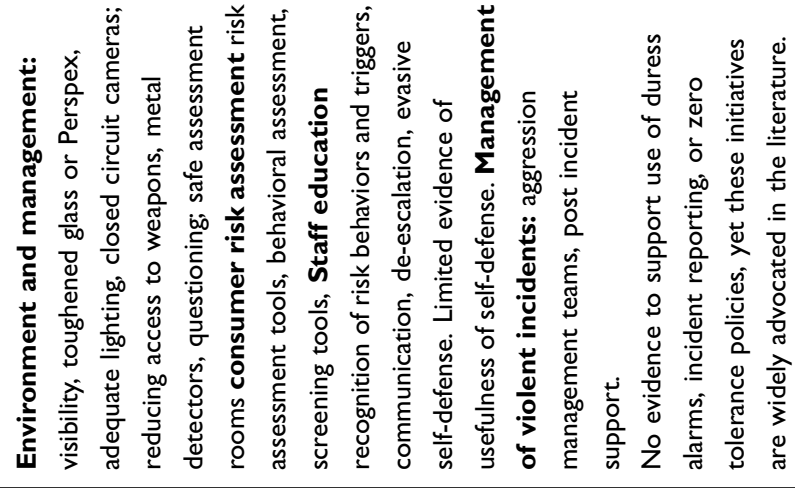 \\
\hline 竞 & 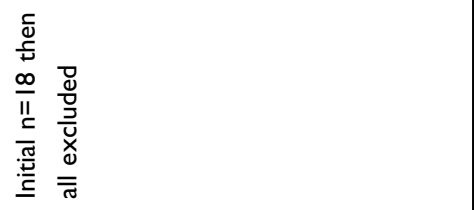 & $\underset{\mathbb{1}}{\underline{I}}$ \\
\hline 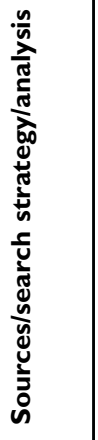 & 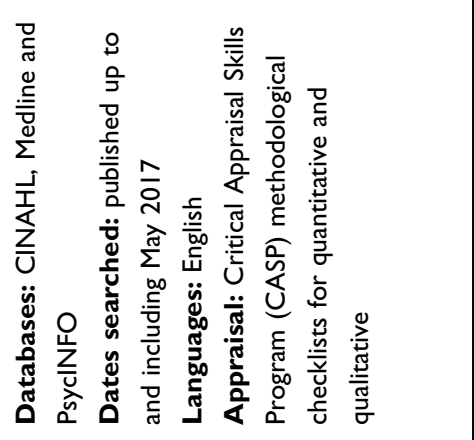 & 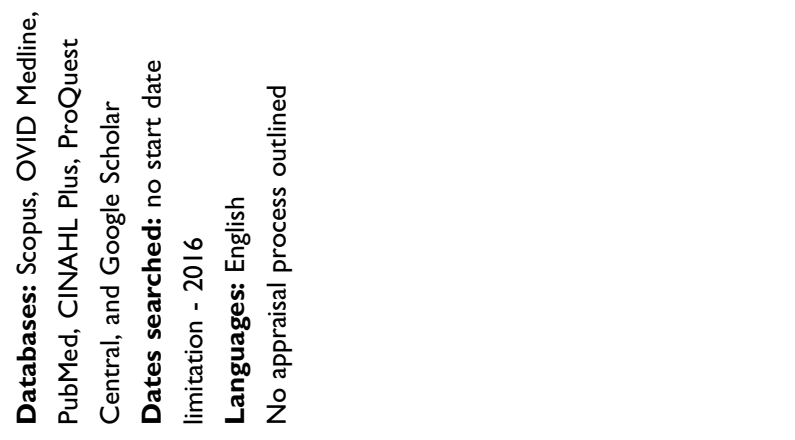 \\
\hline$\frac{\varepsilon}{\frac{\xi}{\alpha}}$ & 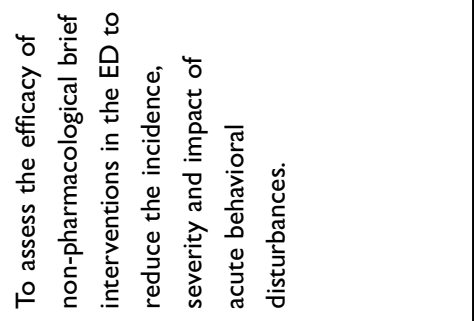 & 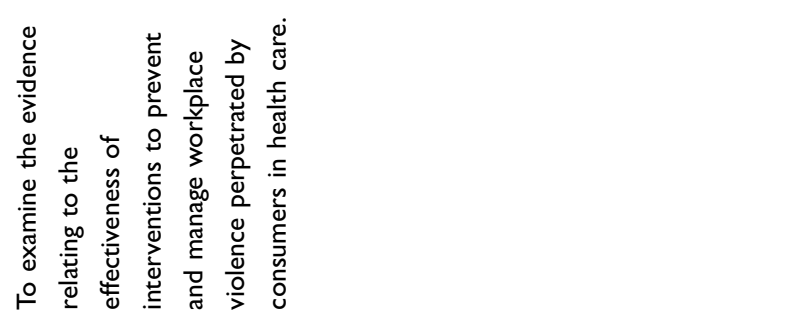 \\
\hline 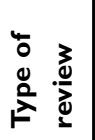 & 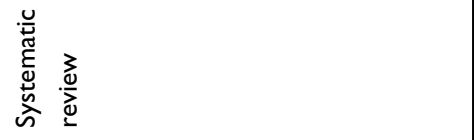 & 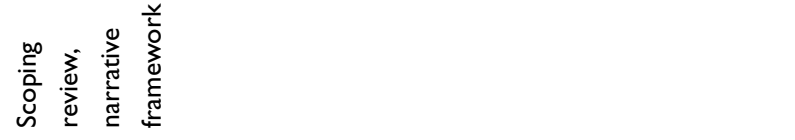 \\
\hline 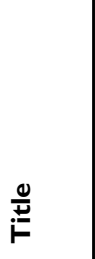 & 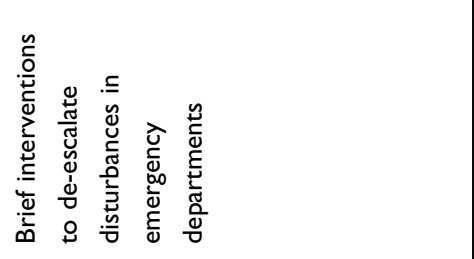 & 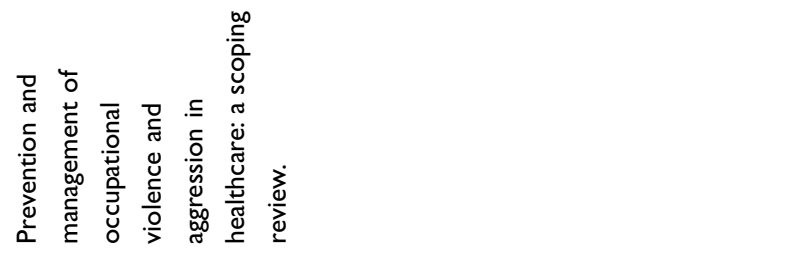 \\
\hline 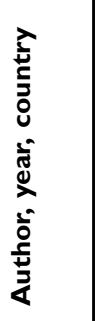 & 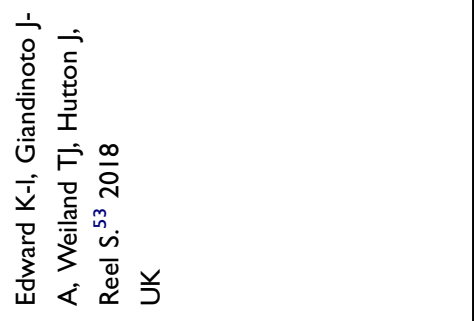 & 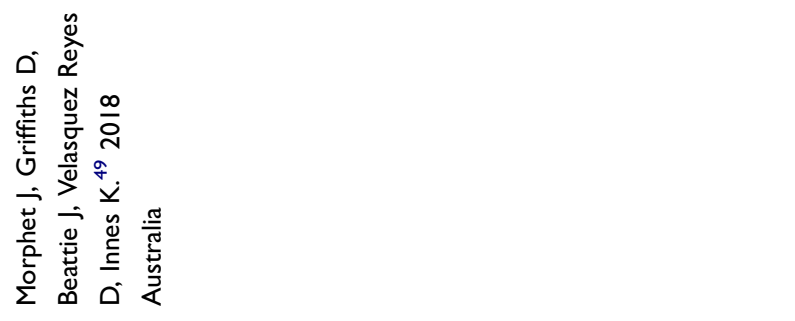 \\
\hline
\end{tabular}


such as agitation and aggression, in the ED. A robust process following the PRISMA guidelines identified 18 articles which appeared to fulfill the inclusion criteria, but following detailed consensus review it was clear that none were adequate to address the research question. The success of BI in ED in response to substance misuse and intimate partner violence was suggested as indicating the potential for the development of a similar intervention for aggression, and a review of the materials that had been identified indicated further inter-professional education on de-escalation was an area for consideration. However, the authors noted that the evidence regarding the benefits and efficacy of education interventions for aggression management remains inconclusive. Many authors have focused on education and training interventions, and this is reflected in the existing reviews. Farrell and $\mathrm{Cubit}^{46}$ carried out a detailed analysis in 2005 of existing aggression management programs (AMP) for health-care staff, creating an assessment tool utilizing 13 major content areas derived from the recommendations of key professional and industrial organizations. Their criteria for material to be covered in such courses included:

- Orientation to the workplace environment (including policies, grievance procedures)

- Causes of aggression, behavioral theories, disease processes

- Types of aggression: physical, psychological, verbal abuse

- Identification of potentially violent situations/risk assessment

- Communication, therapeutic relationships, defusing techniques

- Pharmacological management

- Assertiveness training, self-defense, physical restraint

- Risks of applying restraint

- Seclusion

- Legal and ethical concepts

- Leadership and management

- Debriefing and counseling post-event

- "Costs" of violence

They identified and critiqued 28 existing AMP programs, noting that no course covered all of the identified areas. Those topics most widely covered were causes $(n=23)$, communication $(\mathrm{n}=20)$ and physical techniques, risk assessment and legal issues $(n=20)$. The other sections were unevenly represented, with very low levels of content evident for pharmacological management, issues associated with restraint, seclusion or the "costs" of aggression. However, while the authors acknowledge that the review has constraints associated with the degree of information available to them - this was limited to published information on course content, and information gained from speaking with colleagues and course providers - it is unclear what degree of consistency or additional information may be present within the courses, or what assessment is undertaken to determine the impact or effectiveness of such training. This is outside the intentions of their review, and the authors do appropriately acknowledge that there is a lack of evidence surrounding AMP ability to change and maintain staff behavior in the short, medium or long term. Whatever AMP course is implemented, they suggest it should include a systematic evaluation, seeking more than just the commonly assessed level of participant satisfaction. The need to link to an organizational level of support for any interventions is also highlighted, with acknowledgment that without evidence of managerial support AMP are likely to offer no more than a "band-aid solution".

Aggression management programs were also reviewed by Heckerman et $\mathrm{al}^{52}$ in 2014 , who looked specifically for studies which included an evaluation using a before/after design. These authors assessed the methodological quality of each of the nine studies that met their inclusion criteria, identifying two as weak, six as moderate and one as having a strong study design. The programs were described as being similar in terms of content, with all including reference to theoretical models of aggression, causes, triggers, prevention, management, and legal factors, communication and de-escalation. Six of the programs included physical safety in the form of breakaway techniques and four included post-event debriefing.

All studies identified participant self-perceived improvements in attitude, confidence or external competence assessment by means of written, oral or scenario testing. However, statistical significance was not achieved in the majority of studies, and changes were not consistent over time. Two of the studies collected data on incident rates and impact, which showed an initial decrease in rates of aggressive acts, but this could not be shown to be maintained at three and six months. The authors summarized their findings, noting that the AMP training did provide evidence of increased knowledge about risk management and management of aggression, but no sustained long-term reduction in workplace violence. While 
the programs were shown to boost confidence, caution needs to be exercised, remembering that confidence is not always associated with judgment and competence. Overall, the importance of seeking cultural change across all levels within an organization was emphasized in order to move toward long-term reduction in violence.

A scoping review was carried out in 2018 by Morphet el al, ${ }^{49}$ looking to identify the evidence relating to the effectiveness of interventions to prevent and manage workplace violence, perpetrated by health-care consumers. This review used the PRISMA guidelines and process, and included identification of several aspects directly relevant to the management of the aggressive patient. This included consideration of the role and usefulness of staff education, recognition of risk behaviors and triggers, the importance of communication and de-escalation, and evasive self-defense. Nine studies were identified which included evaluation of outcomes. This review identified evidence in support of education related to workplace violence, finding support for improved recognition of at-risk behavior, and improved communication and de-escalation skills. There was no evidence that self-defense training decreased workplace violence, and studies of breakaway training techniques identified that participants were unable to apply the skills in a scenario simulation.

Elements relating to education and training were also raised in several of the other reviews, to a lesser extent.

The review by d'Ettorre et $\mathrm{al}^{35}$ uses a systematic approach to the review process and summary. Within this overview, the authors refer to 60 papers identified, assessed, and assigned to categories relating to risk assessment, occurrence rates, risk management, and physical/ non-physical consequences. Within the risk management section $(n=29), 19$ papers were identified that considered interventions targeted at staff. These included the establishment of patient relationships, communication, and education programs. Particular forms of education and relative effectiveness, with an emphasis on more dynamic and interactive modes, were suggested as having greater efficacy. The use of inter-professional team-based simulation was mentioned as a particularly useful mode of education. Unfortunately, there was limited evidence of specific assessment of the individual studies included or the evidence base underpinning them.

Three staff training programs were assessed as part of the Kynoch et $\mathrm{al}^{48}$ systematic review, which sought to establish best practice in the prevention and management of aggressive behaviors in patients admitted in hospital settings. The study settings covered a range of areas, including ED. While acknowledging that the study designs did not provide for high levels of evidence, they were able to make a level 3 finding (that is, derived from observational-analytic designs) that staff training improves selfefficacy and assists in managing aggressive patients. Five of the studies included in the review by Anderson et $\mathrm{al}^{32}$ related to the improvement of different skill sets; four related to staff, and while there was some reference to teamwork, these were essentially focused on individual management responses to aggression. The fifth study was aimed at providing further information to health consumers about the functioning of the $\mathrm{ED}$, on the assumption that better-informed individuals are likely to be less frustrated, and potentially less aggravated. The authors identified that the "aggregated recommendations are weak or dubious, given the design and execution limitations of several studies" (p.2527). Reference to education, communication strategies or training needs are also made within the remaining reviews, but to a much briefer extent.

\section{Environmental considerations}

Following on from education and training, the majority of the reviews identified to some degree the role of environment, either physical or social, in their material. The earliest of the included systematic reviews, that of Stirling et al in $2001,{ }^{55}$ discusses the role of security presence in the form of individuals, and also the impact of environmental adjuncts, and architectural design. This includes reference to the increasing use of technological devices, such as CCTV, personal alarms, and central alarm systems. The importance of developing relationships with security services and local law enforcement agencies/police was identified, and the different roles and opportunities associated with this, including having police and security presence in the ED and police dog patrols in the ED. Overall, the authors found that there had been very few studies which actually assessed the effect of security interventions in reducing violence. These general aspects continue to be represented in the subsequent studies.

Physical limitations associated with ED layout, design, building materials, signage, and available space were all acknowledged within the reviews as contributing not only to the prevalence of violence and the resulting escalation of patient aggression, but also the capacity for managing this. Standard prevention, risk mitigation and opportunities for de-escalation were 
identified, including increased visibility (either through closed-circuit TV, cameras, or toughened glass/ Perspex) $)^{35,49,55}$ controlled access to sensitive/treatment areas; personal alarms, panic buttons, 24-h presence of on-site security, appropriately trained staff and/or presence of police. ${ }^{35,47,49,55,57}$

An extensive scoping review carried out on English language literature published between 1995 and 2016 identified a final sample of 20 research articles, suitable to examine evidence for the effectiveness of interventions to prevent and manage workplace violence perpetrated by consumers in health care. ${ }^{49}$ Of particular relevance, this review had as its primary outcome of interest the incidence of workplace violence (WPV) following the intervention. Broad categories addressed included environmental risk management, which was found to include sub-categories of increased visibility, weapons access, and safe assessment rooms; consumer risk assessment; staff education; and management of violent incidents including two sub-categories: aggression management teams and post-incident support. The authors suggest there is evidence to support the use of education in addressing WPV; however, there is no indication that this reached statistical significance in the quantitative studies, and others are cited with what appears to be self-rated attitude change or competence improvement. Two included studies look at the use of behavioral management teams (BMT), but these are largely descriptive in nature, with both noting at times the need to include restraint. There were no adverse outcomes from this. These two studies were from 2009 and 2012, both from Australia. The review by Martinez $^{57}$ also refers to a BMT approach, citing a 2015 study, suggesting an $11 \%$ reduction in restraint use. Each of the BMT responses involved activating "codes" which had an associated color, however, each used a different color (black, gray, green) highlighting the concern associated with the lack of consistent/consensus color codes within health-care settings. ${ }^{62}$

Several studies identified within the various reviews referred to the possibility of using "safe rooms", "behavioral disturbance rooms", "low stimulus environments" or "seclusion" and this was typically related to the effect of noisy, chaotic, and overcrowded environments ${ }^{48,49,51}$ associated with long waits and poor communication. These specific types of room or environment were seen as options for placement of escalating patients, identified as potentially or already aggressive, and where safer management could be achieved. ${ }^{23}$ Difficulties were acknowledged around access to such spaces and lack of evidence regarding their effectiveness in the ED setting, due to poor quality evidence. Use of these spaces was often linked to the use of physical or chemical restraint, and this further limited the ability to identify the independent effectiveness of each aspect of the intervention. This physical context was further associated with the culture often present within EDs, which saw a default position of management in terms of reactive rather than pro-active intervention. ${ }^{32,51}$ The reactive options presented range from de-escalation through to various forms of restraint. The assumption that restraint remained an ultimate option was present in many of the individual studies within the reviews, but the level of evidence in support of these more interventional techniques is weak..$^{48,51,54}$ Nelstop et $\mathrm{al}^{54}$ carried out a seminal review in 2006 which remains well cited, in relation to the development of NICE guidelines ${ }^{63}$ and recommendations regarding physical restraint and seclusion. Specifically, their review looked at whether these were effective interventions for the short-term management of disturbed/violent behavior. This review incorporated 36 studies and identified that there was little empirical evidence that could be cited in support of the effectiveness and safety of seclusion or restraint as interventions. Their findings noted such interventions should be used with caution, and only after "all other methods to calm a situation have failed" (p.14). Kynoch et al acknowledge that the use of "as required" medications and physical restraint may be effective in minimizing harm to patients and staff, but also point out the lack of high-quality studies conducted in the acute care setting. ${ }^{48}$

A number of the reviews identified a series of studies from the USA that looked at the use of metal detectors and the routine check for and removal of weapons, although all noted these studies had varied effectiveness reported. ${ }^{32,49,55,57}$ The use of metal detectors was noted to provide mixed effect, with some staff and consumers finding this reassuring, and others noting although weapons were identified and removed, overall levels of violence were not reduced and potential negative publicity could result. The majority of these studies were from the 1990s. More recent works remain unclear as to the utility of this approach. While subsequent studies have provided evidence of increased rates of weapons confiscation, staff and consumer perceptions of safety, there are no evaluation studies linking to possible impact in terms of violence reduction. It is also noted that these processes are not able to cover all means of entry to the ED, most notably not covering 
access via ambulance. ${ }^{60}$ A 2019 study of US hospital security programs surveyed members of the International Association for Healthcare Security \& Safety, covering a wide geographical range. Although only receiving 77 completed surveys (estimated $4 \%$ of possible responses) this study identified the most commonly used weapons and deterrents by security staff within US hospitals were handcuffs (78\%), hand-held metal detectors/wands (48\%), tasers (38\%) clubs (35\%), pepper spray $(27 \%)$, and guns $(26 \%){ }^{61}$

Alternatives to direct screening through the use of metal detectors for weapons presence is the suggestion of more direct questioning of ED patients, and the increased use of risk assessment tools. This is often suggested as an option for triage nurses to initiate, and again met with mixed response and limited evidence of efficacy.

\section{Policies/overview level}

In addition to the more specific aspects identified, the reviews generally included reference to the importance of gaining a higher level of support or "buy-in" if any significant culture change or long-term management of violence and aggression was to be achieved. ${ }^{32,52}$ This was expressed in terms of the need for policies, pathways and sufficient back up to enable change and management strategies to be introduced. This was seen at both the micro and macro level, with recommendations around the importance of developing workplace protocols, alongside the need for active involvement in government legislation and policymaking. ${ }^{32,47,52}$

\section{Final meta-synthesis}

The final meta-synthesis of the articles reviewed identified the following themes, summarized in Table 3.

\section{Clinical implications}

There is a recognized issue with violence and aggression in the health-care setting, and more specifically with regard to the management of the aggressive patient presenting in the acute environment. What is lacking, however, is a clear evidence base of interventions to draw on in responding to this situation. While not claiming to be exhaustive, this review and meta-synthesis has demonstrated concern expressed in the current literature

Table 3 Meta-synthesis, themes, and codes

\begin{tabular}{|c|c|c|}
\hline Meta-synthesis & Themes & Codes \\
\hline The need for research & $\begin{array}{l}\text { - Focused critical review } \\
\text { - Recognized outcome measures } \\
\text { - Consistent processes } \\
\text { - Quality research looking at effectiveness } \\
\text { - Evidence-based intervention } \\
\text { - Recognizing limitations of current } \\
\text { practice }\end{array}$ & $\begin{array}{l}\text { Evidence-based } \\
\text { Consensus outcomes } \\
\text { Measurable outcomes } \\
\text { Critical appraisal } \\
\text { Consistency in practice } \\
\text { Research based } \\
\text { Lack of evidence } \\
\text { Poor quality } \\
\text { Consequences }\end{array}$ \\
\hline Educational interventions & $\begin{array}{l}\text { - Prioritizing education opportunities } \\
\text { - Importance of communication } \\
\text { - Establishing therapeutic relationships } \\
\text { - Recognizing risk } \\
\text { - De-escalation skills }\end{array}$ & $\begin{array}{l}\text { Accurate reporting } \\
\text { Communication skills } \\
\text { Physical intervention } \\
\text { Verbal skills } \\
\text { Standardized techniques } \\
\text { Systematic evaluation } \\
\text { Risk and behavioral assessment } \\
\text { Self-efficacy }\end{array}$ \\
\hline Challenging workplace design/processes & $\begin{array}{l}\text { - Managing physical layout } \\
\text { - Minimizing stressful environments } \\
\text { - Changing workplace culture } \\
\text { - Evidence-based processes } \\
\text { - Engaged organizations }\end{array}$ & $\begin{array}{l}\text { Managerial support } \\
\text { Organizational buy-in } \\
\text { Policies and procedures } \\
\text { Behavior management Teams } \\
\text { Security response } \\
\text { Leadership } \\
\text { Support } \\
\text { Environment }\end{array}$ \\
\hline
\end{tabular}


regarding the poor overall quality of available research, and its low evidence base as regards capacity for informing clinical recommendations. The studies considered utilized a range of methods, but there remains a limited number of interventional studies, and very few which offer a longitudinal approach with objectively measured outcomes. This limited evidence is further supported by the 2015 updated NICE Guideline on Violence and Aggression ${ }^{63}$ which includes Emergency Department settings, but found only two works that met the inclusion criteria, and which provided low-level evidence only in regard to management strategies and training programs. The works included were the review by Anderson $^{32}$ which was found to be inconclusive about whether management strategies/training programs reduced rates of violence and aggression, and a single observational study with low-level evidence suggesting partial support for staff training programs having an impact on staff attitudes.

Of the reviews included in this meta-synthesis, five formed recommendations as part of the summary of their works, while the remainder offered concluding statements or sections which made informal suggestions for practice. The majority of these related to the need for further research, or were in the form of limiting or negative statements, acknowledging the lack of sufficient evidence to support initiatives. ${ }^{32,48,54}$ These included strong overarching statements such as "In the absence of well-controlled studies, no recommendations can be made about the efficacy of nonpharmacological strategies to manage ABDs [acute behavioral disturbances] within EDs" (p.660), ${ }^{50}$ and that there is "no strong evidence to support the implementation of interventions to prevent and manage patient aggression in acute care settings ..." (p.84). ${ }^{48}$ These are alongside more specific comments around training programs, with summaries of limited supporting evidence, ${ }^{48,52}$ and acknowledgment that there is insufficient evidence regarding physical intervention or seclusion ${ }^{54}$ or the use of duress alarms and zero-tolerance policies. ${ }^{49}$

While acknowledging that the evidence is limited, and that findings at times seem incomplete or contradictory, these reviews, as with others, continue to offer practice suggestions. Some of these are derived from clear guidelines and linked to evidence standards; however, others are less robustly expressed. Despite this lack of consistency and consensus within the literature, it remains commonplace to see new studies, expert opinion pieces and editorials outlining practices, "hints" and guidelines for clinical practice. There remain a number of potential responses, which can be linked to various theoretical approaches. ${ }^{64}$ A useful way of conceptualizing these is to consider the Haddon matrix overview, and then identify the relevant elements that may relate to the specific problem being considered. When looking at the management of the aggressive patient, this fits predominately within the "event" phase of the matrix, but aspects from other levels are also likely to be of use. While many of the responses which are currently in use appear to be grounded in common sense, in the absence of an evidential base it is difficult to evaluate these. Inevitably, in the absence of standards around care and interventions, when faced with an unavoidable situation, the only response is to do the best possible in the circumstances. The pragmatic approach and ability to respond with innovation and flexibility are core skills of emergency clinicians, and many of these practices may prove to be highly effective in the future, but they may also be unsuccessful. What is important is to take such steps knowingly. Where possible, unproven measures should be recognized, and outcomes followed in order to add to the knowledge base.

\section{Limitations and Recommendations}

There are limitations with this review; these include those associated with the included articles: that the studies are limited to English language only, and the exclusion of works that focused on pharmacological interventions. In addition, it is acknowledged that due to the differing study outcomes represented in the included articles a meta-analysis was not feasible, and therefore it has not been possible to develop an evidence-based intervention strategy. It is likely that a broader approach, including some of the studies which were predominately focused on other clinical areas, topics or which had not sought to evaluate the materials reviewed, might offer additional insight.

\section{Research interventions}

The importance of continuing to focus on research within the clinical setting is clear; practitioners are otherwise left to devise ad hoc interventions or to follow historical trajectories simply because this is the way things "have always been done". While few would question the benefits of evidence-based practice, the ability to generate a research base when under pressure from an increasingly chaotic work environment makes the willingness to take part in sound research practices challenging. What is suggested, then, is that clinicians look to practical steps that allow them to engage in the furthering of evidence collection and questioning of current practices. 
1. To review current practices within the clinical setting, and identify the underpinning evidence (or lack of) in own areas.

2. To consider how practical research can be carried out in the busy ED - even simple "before and after" studies, audit or similar processes so that at a minimum examination of new or altered practices can occur.

3. To include research into best practice for the management of violence and responses to violence and aggression as priorities in departmental and organizational Research and Development agendas.

4. To actively engage in supporting research opportunities, and making connections to enable the development of robust quantitative and qualitative research strategies.

\section{Conclusion}

In summary, despite the continued focus on violence and aggression, and the recognition of the significance of this in the setting of emergency care, there is a lack of robust evidence to guide clinicians. This creates the need for all working in this area to contribute to and support the ongoing development of evidence-based, clinically relevant practice.

\section{Disclosure}

The authors report no conflicts of interest in this work.

\section{References}

1. Schnapp BH, Slovis BH, Shah AD, et al. Workplace violence and harassment against emergency medicine residents. West J Emerg Med. 2016;17(5):567-573. doi:10.5811/westjem.2016.6.30446

2. Whelan T. The escalating trend of violence toward nurses. $J$ Emerg Nurs. 2008;34(2):130-133. doi:10.1016/j.jen.2007.05.018

3. Midlow-Porto V. Violence in the ED reaches a crisis point. Emerg Physicians Monthly. 2016.Available from: https://epmonthly.com/arti cle/violence-ed-reaches-crisis-point/. Accessed: July 23, 2019.

4. Chapman R, Styles I. An epidemic of abuse and violence: nurse on the front line. Accid Emerg Nurs. 2006;14(4):245-249. doi:10.1016/j. aaen.2006.08.004

5. Ramacciati N, Ceccagnoli A, Addey B, Lumini E, Rasero L. Interventions to reduce the risk of violence toward emergency department staff: current approaches. Open Access Emerg Med. 2016;8:1727. doi:10.2147/OAEM.S69976

6. Baydin A, Erenler AK. Workplace violence in emergency department and its effects on emergency staff. Int $J$ Emerg Ment Health Human Resilience. 2014;16(2):66-68. doi:10.4172/1522-4821.1000112

7. Ferns T. Violence in the accident and emergency department-an international perspective. Accid Emerg Nurs. 2005;13(3):180-185. doi:10.1016/ j.aaen.2005.03.005

8. Ogundipe KO, Etonyeaku AC, Adigun I, et al. Violence in the emergency department: a multicentre survey of nurses' perceptions in Nigeria. Emerg Med J. 2013;30(9):758-762. doi:10.1136/emermed-2012-201541
9. Sakr M, Wardrope J. Casualty, accident and emergency, or emergency medicine, the evolution. J Accid Emerg Med. 2000;17:314319. doi:10.1136/emj.17.5.314

10. Suter RE. Emergency medicine in the United States: a systemic review. World J Emerg Med. 2012;3(1):5-10. doi:10.5847/wjem. j.1920-8642.2012.01.001

11. Chung $\mathrm{CH}$. The evolution of emergency medicine. Hong Kong $J$ Emerg Med. 2000;8(2):84-89. doi:10.1177/102490790100800204

12. Fleischmann T, Fulde G. Emergency medicine in modern Europe. Emerg Med Australas. 2007;19(4):300-302. doi:10.1111/j.17426723.2007.00991.x

13. Fares S, Irfan FB, Corder RF, et al. Emergency medicine in the United Arab Emirates. Int J Emerg Med. 2014;7(4). doi:10.1186/ 1865-1380-7-4

14. Reynolds TA, Mfinanga JA, Sawe HR, Runyon MS, Mwafongo V. Emergency care capacity in Africa: a clinical and educational initiative in Tanzania. J Public Health Policy. 2012;33(Suppl 1):S126S137. doi:10.1057/jphp.2012.41

15. Pothiawala S, Anantharaman V. Academic emergency medicine in India. Emerg Med Australas. 2013;25(4):359-364. doi:10.1111/17426723.12095

16. ENA. ENA Position Statement. Violence in the Emergency Department. Ilinois: Emergency Nursing Association; 2014.

17. Australasian College for Emergency Medicine. Violence in Emergency Departments. Melbourne, Australia: ACEM; 2018.

18. Kowalenko T, Gates D, Gillespie GL, Succop P, Mentzel TK. Prospective study of violence against ED workers. Am J Emerg Med. 2013;31(1):197-205. doi:10.1016/j.ajem.2012.07.010

19. Burchill CN, Bena J, Polomano RC. Psychometric testing of the personal workplace safety instrument for emergency nurses. Worldv Evid-Based Nurs. 2018;15(2):97-103. doi:10.1111/wvn.12265

20. Gillespie GL, Gates DM, Berry P. Stressful incidents of physical violence against emergency nurses. Online J Issues Nurs. 2013;18 (1):Manuscript 2.

21. Hodge AN, Marshall AP. Violence and aggression in the emergency department: a critical care perspective. Aust Crit Care. 2007;20 (2):61-67. doi:10.1016/j.aucc.2007.03.001

22. Gilchrist H, Jones SC, Barrie L. Experiences of emergency department staff: alcohol-related and other violence and aggression. Australas Emerg Nurs J. 2011;14(1):9-16. doi:10.1016/j. aenj.2010.09.001

23. Pich JV, Kable A, Hazelton M. Antecedents and precipitants of patient-related violence in the emergency department: results from the Australian VENT Study (Violence in Emergency Nursing and Triage). Australas Emerg Nurs J. 2017;20(3):107-113. doi:10.1016/j. aenj.2017.05.005

24. Angland S, Dowling M, Casey D. Nurses' perceptions of the factors which cause violence and aggression in the emergency department: a qualitative study. Int Emerg Nurs. 2014;22(3):134-139. doi:10.1016/ j.ienj.2013.09.005

25. Morphet J, Griffiths D, Plummer V, Innes K, Fairhall R, Beattie J. At the crossroads of violence and aggression in the emergency department: perspectives of Australian emergency nurses. Aust Health Rev. 2014;38(2):194-201. doi:10.1071/AH13189

26. Medley DB, Morris JE, Stone CK, Song J, Delmas T, Thakrar K. An association between occupancy rates in the emergency department and rates of violence toward staff. J Emerg Med. 2012;43(4):736744. doi:10.1016/j.jemermed.2011.06.131

27. Pich J, Hazelton M, Sundin D, Kable A. Patient-related violence against emergency department nurses. Nurs Health Sci. 2010;12 (2):268-274. doi:10.1111/j.1442-2018.2010.00525.x

28. Lyneham J. Violence in New South Wales emergency departments. Aust J Adv Nurs. 2000;18(2):8-16.

29. Ashton RA, Morris L, Smith I. A qualitative meta-synthesis of emergency department staff experiences of violence and aggression. Int Emerg Nurs. 2018;39:13-19. doi:10.1016/j.ienj.2017.12.004 
30. Copeland D, Henry M. The relationship between workplace violence, perceptions of safety, and Professional Quality of Life among emergency department staff members in a Level 1 Trauma Centre. Int Emerg Nurs. 2018;39:26-32. doi:10.1016/j.ienj.2018.01.006

31. Wolf LA, Delao AM, Perhats C. Nothing changes, nobody cares: understanding the experience of emergency nurses physically or verbally assaulted while providing care. J Emerg Nurs. 2014;40 (4):305-310. doi:10.1016/j.jen.2013.11.006

32. Anderson L, FitzGerald M, Luck L. An integrative literature review of interventions to reduce violence against emergency department nurses. J Clin Nurs. 2010;19(17-18):2520-2530. doi:10.1111/j.13652702.2009.03144.x

33. Lau JB, Magarey J. Review of research methods used to investigate violence in the emergency department. Accid Emerg Nurs. 2006;14 (2):111-116. doi:10.1016/j.aaen.2006.02.003

34. Wilkes L, Mohan S, Luck L. Development of a violence tool in the emergency hospital setting. Nurse Res. 2010;17(4):70. doi:10.7748/ nr2010.07.17.4.70.c7926

35. D'Ettorre G, Pellicani V, Mazzotta M, Vullo A. Preventing and managing workplace violence against healthcare workers in Emergency Departments. Acta Biomed. 2018;89(4-S):28-36. doi:10. 23750/abm.v89i4-S.7113

36. Kling R, Coroiere M, Milord R, et al. Use of a violence risk assessment tool in an acute care hospital effectiveness in identifying violent patients. AAOHN J. 2006;54(11). doi:10.1177/ 216507990605401102

37. Gillespie GL, Pekar B, Byczkowski TL, Fisher BS. Worker, workplace, and community/environmental risk factors for workplace violence in emergency departments. Arch Environ Occup Health. 2017;72(2):79-86. doi:10.1080/19338244.2016.1160861

38. Pati D, Pati S, Harvey TE Jr. Security implications of physical design attributes in the emergency department. HERD. 2016;9(4):50-63. doi: $10.1177 / 1937586715626549$

39. Design Council, Department of Health. Reducing Violence and Aggression in $A \& E$; 2011.Available from: designcouncil.org.uk/sites/ default/files/asset/document/ReducingViolenceAndAggressionInAandE. pdf. Accessed July 23, 2019.

40. Downey LV, Zun LS, Gonzales SJ. Frequency of alternative to restraints and seclusion and uses of agitation reduction techniques in the emergency department. Gen Hosp Psychiatry. 2007;29(6):470 474. doi:10.1016/j.genhosppsych.2007.07.006

41. Swickhamer C, Colvig C, Chan SB. Restraint use in the elderly emergency department patient. J Emerg Med. 2013;44(4):869-874. doi:10.1016/j.jemermed.2012.02.080

42. Mitra B, Nikathil S, Gocentas R, Symons E, O’Reilly G, Olaussen A. Security interventions for workplace violence in the emergency department. Emerg Med Australas. 2018;30(6):802-807. doi:10.11 11/1742-6723.13093

43. Wilson MP, Nordstrom K, Vilke GM. The agitated patient in the emergency department. Curr Emerg Hosp Med Rep. 2015;3(4):188194. doi:10.1007/s40138-015-0087-5

44. Barnett DJ, Balicer RD, Blodgett D, Fews AL, Parker CL, Links JM. The application of the Haddon matrix to public health readiness and response planning. Environ Health Perspect. 2005;113(5):561-566. doi: $10.1289 /$ ehp. 7491

45. Moher D, Liberati A, Tetzlaff J, Altman DG, The PRISMA Group. Preferred reporting items for systematic reviews and meta-analyses: the PRISMA statement. PLoS Med. 2009;6(7):e1000097. doi:10.13 71/journal.pmed.1000097

46. Farrell G, Cubit K. Nurses under threat: a comparison of content of 28 aggression management programs. $J$ Mental Health Nurs. 2005;14:44-53. doi:10.1111/j.1440-0979.2005.00354.x
47. Lau J, Magarey J, McCutcheon H. Violence in the emergency department A literature review. Aust Emerg Nurs J. 2004;7(2):27-37. doi:10.1016/S1328-2743(05)80028-8

48. Kynoch K, Wu CJ, Chang AM. Interventions for preventing and managing aggressive patients admitted to an acute hospital setting: a systematic review. Worldviews Evid Based Nurs. 2011;8(2):76-86. doi:10.1111/j.1741-6787.2010.00206.x

49. Morphet J, Griffiths D, Beattie J, Velasquez Reyes D, Innes K. Prevention and management of occupational violence and aggression in healthcare: a scoping review. Collegian. 2018;25(6):621-632. doi:10.1016/j.colegn.2018.04.003

50. Weiland TJ, Ivory S, Hutton J. Managing acute behavioural disturbances in the emergency department using the environment, policies and practices: a systematic review. West J Emerg Med. 2017;18 (4):647-661. doi:10.5811/westjem.2017.4.33411

51. van der Zwan R, Davies L, Andrews D, Brooks A. Aggression and violence in the ED: issues associated with the implementation of restraint and seclusion. Health Promot J Aust. 2011;22(2):124-127.

52. Heckemann B, Zeller A, Hahn S, Dassen T, Schols JM, Halfens RJ. The effect of aggression management training programmes for nursing staff and students working in an acute hospital setting. A narrative review of current literature. Nurse Educ Today. 2015;35 (1):212-219. doi:10.1016/j.nedt.2014.08.003

53. Edward K-L, Giandinoto J-A, Weiland TJ, Hutton J, Reel S. Brief interventions to de-escalate disturbances in emergency departments. Br J Nurs. 2018;27(6):322-327. doi:10.12968/bjon.2018.27.6.322

54. Nelstrop L, Chandler-Oatts J, Bingley W, et al.A systematic review of the safety and effectiveness of restraint and seclusion as interventions for the short-term management of violence in adult psychiatric inpatient settings and emergency departments. Worldviews Evid Based Nurs. 2006;3(1):8-18.

55. Stirling G, Higgins JE, Cooke MW. Violence in A\&E departments: a systematic review of the literature. Accid Emerg Nurs. 2001;9:77-85. doi:10.1054/aaen.2000.0204

56. Calow N, Lewis A, Showen S, Hall N. Literature synthesis: patient aggression risk assessment tools in the emergency department. $J$ Emerg Nurs. 2016;42(1):19-24. doi:10.1016/j.jen.2015.01.023

57. Martinez AJS. Managing workplace violence with evidence based interventions. J Psychosoc Nurs. 2016;54(9):31-36.

58. Tishler CL, Reiss NS, Dundas J. The assessment and management of the violent patient in critical hospital settings. Gen Hosp Psychiatry. 2013;35(2):181-185. doi:10.1016/j.genhosppsych.2012.10.012

59. Braun V, Clarke V. Using thematic analysis in psychology. Qual Res Psychol. 2006;3(2):77-101. doi:10.1191/1478088706qp063oa

60. Malka ST, Chisholm R, Doehring M, Chisholm C. Weapons retrieved after the implementation of emergency department metal detection. $J$ Emerg Med. 2015;49(3):355-358. doi:10.1016/j.jemermed.2015.04.020

61. Blando JD, Cramer RJ, Szklo-Coxe M. Hospital security programs and policies related to guns and other weapons. J Healthcare Manag. 2019;64(3):157-166. doi:10.1097/JHM-D-18-00046

62. Prickett KJ, Williams-Prickett K. Plain language emergency alert codes: the importance of direct impact statements in hospital emergency alerts. J Emerg Manag. 2018;16(2):73-79. doi:10.5055/ jem.2018.0356

63. National Institute for Health and Care Excellence. Violence and Aggression Short-term management in mental health, health and community settings (Updated edition). NICE guideline NG10. 2015. Available from: https://www.nice.org.uk/guidance/ng10/evidence/ full-guideline-pdf-70830253. Accessed August 30, 2019.

64. Ramacciati N, Ceccagnoli A, Addey B, Lumini E, Rasero L. Violence towards emergency nurses: a narrative review of theories and frameworks. Int Emerg Nurs. 2018;39:2-12. doi:10.1016/j.ienj. 2017.08.004 


\section{Publish your work in this journal}

The Open Access Emergency Medicine is an international, peerreviewed, open access journal publishing original research, reports, editorials, reviews and commentaries on all aspects of emergency medicine. The manuscript management system is completely online

Submit your manuscript here: https://www.dovepress.com/open-access-emergency-medicine-journal and includes a very quick and fair peer-review system, which is all easy to use. Visit http://www.dovepress.com/testimonials.php to read real quotes from published authors. 